Article

\title{
Are Black Friday Deals Worth It? Mining Twitter Users' Sentiment and Behavior Response
}

\author{
Jose Ramon Saura ${ }^{1}\left(\mathbb{D}\right.$, Ana Reyes-Menendez ${ }^{1, *} \mathbb{C}$ and Pedro Palos-Sanchez ${ }^{2}(\mathbb{D})$ \\ 1 Department of Business Economics, Faculty of Social Sciences and Law, Rey Juan Carlos University, \\ Paseo Artilleros s/n, 28032 Madrid, Spain \\ 2 Department of Financial Economy and Operations Management, University of Seville, 41018 Seville, Spain \\ * Correspondence: ana.reyes@urjc.es
}

Received: 23 July 2019; Accepted: 19 August 2019; Published: 20 August 2019

\begin{abstract}
The Black Friday event has become a global opportunity for marketing and companies' strategies aimed at increasing sales. The present study aims to understand consumer behavior through the analysis of user-generated content (UGC) on social media with respect to the Black Friday 2018 offers published by the 23 largest technology companies in Spain. To this end, we analyzed Twitter-based UGC about companies' offers using a three-step data text mining process. First, a Latent Dirichlet Allocation Model (LDA) was used to divide the sample into topics related to Black Friday. In the next step, sentiment analysis (SA) using Python was carried out to determine the feelings towards the identified topics and offers published by the companies on Twitter. Thirdly and finally, a data-text mining process called textual analysis (TA) was performed to identify insights that could help companies to improve their promotion and marketing strategies as well as to better understand the customer behavior on social media. The results show that consumers had positive perceptions of such topics as exclusive promotions (EP) and smartphones (SM); by contrast, topics such as fraud (FA), insults and noise (IN), and customer support (CS) were negatively perceived by customers. Based on these results, we offer guidelines to practitioners to improve their social media communication. Our results also have theoretical implications that can promote further research in this area.
\end{abstract}

Keywords: information management; business strategy; sentiment analysis; UGC; data mining

\section{Introduction}

In past several decades, numerous studies have investigated the relationship between companies and users through the Internet [1-3]. This relationship, based on user-brand interaction on social networks, is a starting point for the study of the relationship between companies and their customers in digital environments [4]. The content generated by users on the Internet, termed as user-generated content (UGC), has been extensively used by researchers to extract insights and to discover knowledge about digital environments [5]. It is also well known that users use social networks to interact with brands [6].

This digital environment has been consolidated as a new channel for bidirectional communication between brands and their customers [7]. In addition, this online interaction offers many opportunities to obtain data about users' behavior online and to better understand how it can be used by companies to improve their relationship with customers as well as to increase the engagement [8].

In this respect, numerous previous studies have focused on the Black Friday event and analyzed user behavior and companies' marketing strategies [9-11]. On Black Friday event, the world's leading technology companies offer discounts and special promotions to their customers in order to increase sales and enhance their brand value [6,12]. 
In Spain, Black Friday is the most attractive event for $70 \%$ of the population, as compared to other similar events such as Cyber Monday [13]. According to some estimates, 74\% of Spanish people save money to spend exclusively on this event and to purchase on average two and three products. In addition, $88 \%$ of Spanish people trust in the veracity of the sales, which translates into a total average amount of $214 €$ per user [13].

Against this background, the problem that has arisen in recent years is that many companies have used inappropriate promotion and marketing strategies [14]. Specifically, several companies increased their prices several weeks before Black Friday to then lower them and, thus create "offers" [6]. Strategies of this type rendered many social network users critical of these activities $[15,16]$, which resulted in a damaged reputation and other losses for companies [17].

In the present-day ecosystem, social networks are one of the main channels for communication between companies and users $[18,19]$. Based on this assumption, the present study focuses on the analysis of digital marketing and promotion strategies of main technology companies through Twitter on the Black Friday 2018 event in Spain.

It is well known that users develop content on social networks-known as UGC-to express their feelings about the products, services, and brands [20]. These contents are published publicly and summarize the key information that, from the consumer point of view, contains the guidelines for future customers before they make their purchase decisions [21]. To find out what these key issues are, companies can use market studies; however, such studies are time-consuming and expensive [20]. For instance, several studies have demonstrated that relevant research on salient topics in UGC can help executives make decisions [22,23].

In the present study, an original and innovative method is proposed to quickly detect such topics with the use of Support Vector Machines (SVM) and data analysis techniques, focusing on the social network Twitter. The first research question addressed is as follows: What are the main topics in Twitter-based user interactions with the companies that participate in Black Friday? (RQ1).

Previous literature suggests that, on different occasions, understanding consumer sentiment and responses to offers made by companies is key to developing relevant strategies for effective marketing (see Vyas and Uma [24] and Shahijan et al. [25]). The importance of understanding these feelings can allow executives or marketing managers to make decisions based on consumer feedback, including their responses on social networks, such as comments and reviews [26,27]. Therefore, the second research question we address is as follows: What feelings (positive, negative or neutral) are associated with the main UGC topics surrounding the Black Friday event on Twitter? (RQ2).

Furthermore, previous studies $[28,29]$ demonstrated that the communication of companies with their users on social networks should prioritize ways to increase engagement between users and brands [5]. In fact, long-term relationships between companies and users promote user satisfaction with brands and lead to users' sharing positive opinions on the Internet and social networks [30]. These insights help brands to better understand their consumers' behaviors, tastes, and habits [31]. Thus, the third question we seek to answer is as follows: Is it possible to establish casual relationships between the feelings of the engagement of the UGC on Twitter, with the strategies of marketing and promotion of the companies? (RQ3).

To address these questions, we analyzed communication strategies of companies with Twitter clients, as well as seeking to understand the motivations and behavior of users on Twitter. Our aim was to establish whether companies were using relevant marketing strategies in social networks and whether they were appropriately communicating with users. In addition, we aimed to understand major themes and associated feelings in Twitter-based UGC, as well as to find out which companies used better or worse promotional strategies on Twitter, and why.

To this end, we used a three-step data analysis technique to analyze Twitter-based UGC. First, a topic-modeling technique known as Latent Dirichlet Allocation (LDA) was used to divide the sample of the tweets containing the hashtag Black Friday and the name of the companies in topics. Subsequently, sentiment analysis (SA) was performed to detect the feelings associated with the identified topics. 
Finally, in order to evaluate marketing promotions of individual companies, we analyzed the feelings associated with topics in the analyzed UGC per company. The contribution of the present study is that our results bridge a gap in previous literature in which Black Friday event in Spanish companies has not been studied using a knowledge discovery-based approach.

Therefore, the remainder of this research is structured as follows. In Section 2, we review relevant literature. Sections 3 and 4 focus on methodology development and data analysis. In Section 5, we report the findings that are further discussed in Section 6. Conclusions are drawn in Section 7.

\section{Literature Review}

As discussed above, there is extensive previous literature on marketing promotions of specific events, including the Black Friday event on social media. For instance, Thelwall et al. [12] analyzed the mixed feelings associated with Twitter-based user content posted in response to global events of great impact; the results of this study showed how users can 'viralize' content by generating UGC on social networks.

Furthermore, Bell et al. [10] investigated which methods are effective to establish a good marketing strategy for the Black Friday day. This study made it possible to understand different marketing promotion strategies on social platforms based on calling user attention after knowing what their habits and behaviors are on the internet.

Likewise, Stewart et al. [32] analyzed the relationship between Twitter keywords and consumers behavior in relation to daily spending, emphasizing the engagement of companies with users on social networks. The results of this study showed that users can get organized in communities of similar content that arises from the analysis of specific events and within a certain timeframe.

Following this approach, Shuai et al. [33] compared Twitter and Weibo platforms in terms of user performance in response to world events such as Black Friday with the aim of understanding engagement and extracting insights that companies can use for their strategies on the Internet. Moreover, Ahsan et al. [17] analyzed the sentiments associated with visual contents during social events in order to find out how data mining can help visualize and extract knowledge from the data generated on social networks.

In contrast, Chen [34] focused on the analysis of sentiments in Twitter to determine the attitudes of the sender and receiver of the message from the communicative. This study aimed to understand user behavior and responses in this kind of digital ecosystems.

In addition, Khodabakhsh et al. [35] analyzed Twitter user behaviors associated with important events that have a temporary nature, offering useful insights for the analysis of these events on social networks. Similarly, to Khodabakhsh et al. [35], Zhou et al. [36] used sentiment analysis of tweets posted during large social events to identify the feelings related to user actions and communication published on those digital platforms. Following this line of research, Tsolmon et al. [37] proposed a new method to study Twitter-based UGC associated with social events. Furthermore, from the perspective of social impact, Tsytsarau et al. [38] investigated the reaction of social media and user feelings towards new events. Table 1 summarizes previous studies on Black Friday that used sentiment analysis approaches. 
Table 1. Previous studies on Black Friday that used sentiment analysis.

\begin{tabular}{ll}
\hline Authors & Description \\
\hline Choi and Kim [15] & $\begin{array}{l}\text { A study using the sentiment analysis technique to investigate the impact of } \\
\text { breaking events in Twitter. The results of this study demonstrated how } \\
\text { information related to live events can be spread through social networks. }\end{array}$ \\
\hline Cody et al. [16] & $\begin{array}{l}\text { An analysis of public opinions on Twitter. Sentiment analysis was applied to } \\
\text { study tweets with different hashtags related to Black Friday event. } \\
\text { This approach showed how users share UGC content about social media events. }\end{array}$ \\
\hline Khodabakhsh et al. [35] & $\begin{array}{l}\text { A study using sentiment analysis to investigate trends in Twitter, as well as to } \\
\text { analyze "trending topics" during Black Friday event on Twitter. The results } \\
\text { validated a methodological approach to identify the content trends in UGC. }\end{array}$ \\
\hline Tsolmon et al. [37] & $\begin{array}{l}\text { This study focused on the analysis of User Generated Content (UGC) in a social } \\
\text { event in Twitter using data mining techniques to better understand how the } \\
\text { UGC can be analyzed using knowledge discovery techniques. }\end{array}$ \\
\hline Tsytsarau et al. [38] & $\begin{array}{l}\text { A study using big data analysis of Twitter as a prototype, with the focus on the } \\
\text { impact of Twitter on consumer sentiment. The results of this study } \\
\text { demonstrated that social networks can be used to measure sentiment with big } \\
\text { data approaches for UGC analysis. }\end{array}$ \\
\hline
\end{tabular}

\section{Methodology Development}

In the present study, we used an improved three-step methodological procedure innovatively proposed by Saura and Bennett [5]. This process works with algorithms of data analysis and data mining techniques applied to the UGC from social networks. Several previous studies have also used this methodology, which verifies its reliability and accuracy $[39,40]$. As this method uses machine learning and SVMs, technologies need to be continuously improved (see Raghavendra and Mohan [41] and Alfrjani et al. [42] for such attempts).

The primary purpose of this study is discovery, not hypothesis testing and not trying to control variables, but to discover them [6]. Therefore, this research was conducted using a qualitative and explorative approach. This has been done with the design and integration of three different studies as indicated [5].

We analyzed a total of 23 companies, all currently active in Spain operating in the technology sector. In fact, the offers and promotions offered by technology companies are a major reason of why the Black Friday event emerged globally. Our data were Twitter user interactions with these 23 companies throughout the period of 7 days: 3 days prior to the Black Friday 2018 event in Spain, the day of Black Friday, and 3 days after the event $[33,43]$.

Data collection was performed for 20-27 November 2018. To this end, the authors connected to the Twitter API and downloaded a total of $n=5064$ tweets from the interactions and engagement of Twitter users (UGC) with the companies that compose the sample using the hashtag \#BlackFriday.

For data analysis, repeated tweets were eliminated from the dataset [44,45]. In addition, the images and videos containing the collected tweets were not analyzed, since we focused on the analysis of Natural Language Processing (NLP). In addition, retweets were used as independent tweets, because they were supported by different users [5].

We also excluded HTC and Xiaomi companies from the sample, as these two brands do not have public Twitter profiles focused exclusively on the Spanish market.

\section{Components and Data Analysis}

As indicated above, in the present study, we used a methodology divided into three processes. With respect to the first process of analysis, we followed Saura and Bennett [5]. The LDA model used in this research was developed in Python and can be found in Python library LDA 1.0.5 using Gibbs sampling $[45,46]$. 
As indicated in Saura and Bennett [5], LDA is a mathematical model that divides a series of samples (such as documents, texts, comments, reviews, and so forth) into topics. The LDA topic modeling technique was initially developed by Pritchard and Stephens [46] as a machine learning technique for topic modeling. Three years later, it was expanded by Blei et al. [47].

This method measures the frequency of words and the number of times they are repeated in a database [48]. Application of this approach yields a database of words and their frequency of occurrence in the database. Then, the words are divided according to topics $[49,50]$. Finally, the identified topics are named using frequently used words combined into a sentence that makes sense [51].

The next step was a sentiment analysis (SA) algorithm that works with machine learning [5]. This algorithm divides the sample of topics into three feelings: positive, negative, and neutral (see Thelwall et al. [12] and Reyes-Menendez et al. [39]).

Regarding the next step, the Krippendorff's alpha value (KAV) was identified to verify the results reliability [52-54]. This value is the result of training an algorithm that works with machine learning [52]. Depending on the level of success of this algorithm, conclusions based on level of forcefulness can be presented [55]. Understanding how efficient the methodology development is typical analysis approach when working with SVM algorithms [56-58].

KAV should obtain a result equal to or above 0.667 , so that the results indicate that the algorithm has been trained a sufficient number of times, although Krippendorff's [57] indicates that the minimum KAV should be adjusted according to the weight of the conclusions. In this sense, a high KAV could be $\geq 0.800$, while a KAV between the measures $0.667-0.800$ could be used to tentatively define and argue conclusions $[5,56,57]$. The values for each type of conclusion and feeling according to KAV are shown in Table 2.

Table 2. Sentiment analysis and Krippendorff's alpha value (KAV).

\begin{tabular}{cccc}
\hline Conclusions Reliability & Krippendorff's Alpha Value & Sentiment & Average KAV * \\
\hline High & $\alpha \geq 0.800$ & Positive & 0.730 \\
Tentative & $\alpha \geq 0.667$ & Negative & 0.760 \\
Low & $\alpha<0.667$ & Neutral & 0.682 \\
\hline \multicolumn{2}{c}{ * Research Average KAV. }
\end{tabular}

The basic formula for KAV is the relationship characterized by observed disagreement/expected disagreement. In Equation (1), an apparently simple proportion is shown, as the calculation method is computationally very complex [56-58]. The calculation process involves resampling methods such as bootstrapping [57]. The calculations in Equation (1) are explained in depth in Krippendorff [57].

$$
\hat{\alpha} k=\frac{P_{\alpha}^{*}-P_{e}}{1-P_{e}}, \text { where }\left\{\begin{array}{c}
P_{\alpha}^{*}=\left(1-\varepsilon_{\alpha}\right) P_{\alpha}+\varepsilon_{n}, \varepsilon_{n}=\frac{1}{2 n} \\
P_{\alpha}=\sum_{k, l}^{q} W_{k 1 P k 1,} P_{e}=\sum_{k, l}^{q} W k 1^{\pi} k^{\pi} 1
\end{array}\right.
$$

Finally, the third step of the model was textual analysis (TA) that works with data mining techniques [56]. TA aims to identify insights from a complex database with different objectives [6]. These knowledge discovery processes allow companies to improve their strategies or analyze data from different analytic perspectives [57].

For this process, it is important to divide the datasets into nodes [57]. Nodes are manually divided classifiers of information [5]. This process makes it possible to group a database into information nodes according to the associated feelings and to compute the Weight Percentage (WP) of the nodes (i.e., a measure based on the number of times words are repeated in the general database) $[5,51]$. 


\section{Results}

The topics identified in the sample using the LDA approach, the description of the identified themes, the associated feelings and the average KAV of the identified feeling are summarized in Table 3. We also report WP that represents the total weight of the identified topic in the database as indicated.

Table 3. Latent Dirichlet Allocation (LDA) model results and average KAV.

\begin{tabular}{|c|c|c|c|c|}
\hline Topic & Description & Sentiment & KAV & WP \\
\hline $\begin{array}{l}\text { Offers and } \\
\text { discounts }\end{array}$ & $\begin{array}{l}\text { Offers and discounts are grouped by the } \\
\text { companies for the Black Friday event. }\end{array}$ & Neutral & 0.681 & 4.50 \\
\hline $\begin{array}{l}\text { Exclusive } \\
\text { promotions }\end{array}$ & $\begin{array}{l}\text { Exclusive promotions that have as a characteristic } \\
\text { their duration in hours or minutes for the Black } \\
\text { Friday event. }\end{array}$ & Positive & 0.741 & 3.92 \\
\hline Fraud & $\begin{array}{l}\text { Twitter user comments and opinions about the } \\
\text { scams, frauds, and scams developed by companies } \\
\text { for Black Friday. }\end{array}$ & Negative & 0.784 & 4.21 \\
\hline Insults and Noise & $\begin{array}{l}\text { Insults and negative noise from companies in } \\
\text { response to which users experience their anger } \\
\text { because they feel cheated. }\end{array}$ & Negative & 0.807 & 3.01 \\
\hline Smartphones & $\begin{array}{l}\text { One of the main topics on which offers and } \\
\text { discounts are received. }\end{array}$ & Positive & 0.719 & 2.97 \\
\hline $\begin{array}{l}\text { Computers } \\
\text { accessories }\end{array}$ & $\begin{array}{l}\text { Part of the main topics on which offers and } \\
\text { discounts are received on Black Friday. }\end{array}$ & Neutral & 0.684 & 2.41 \\
\hline Customer Support & $\begin{array}{l}\text { Personal attention to Twitter users and their } \\
\text { complaints. }\end{array}$ & Negative & 0.691 & 1.09 \\
\hline
\end{tabular}

The results obtained using SA to the UGC related to each company are summarized in Table 4 . As mentioned above, we excluded HTC and Xiaomi from the list of companies, as these two brands do not have a public Twitter profile focused specifically on the Spanish market [49].

Table 4. Results of sentiment analysis and average KAV.

\begin{tabular}{lccccc}
\hline Companies & Tweets & Positive & Negative & Neutral & KAV \\
\hline Acer & 4 & 3 & - & 1 & 0.989 \\
Amazon & 3077 & 869 & 1398 & 813 & 0.791 \\
Asus & 6 & 3 & 3 & - & 0.970 \\
BQ & 111 & 52 & 19 & 40 & 0.863 \\
Carrefour & 10 & 3 & 5 & 2 & 0.989 \\
Ebay & 30 & 15 & 8 & 7 & 0.814 \\
El Corte Inglés & 186 & 38 & 82 & 66 & 0.748 \\
Fnac & 68 & 53 & 5 & 10 & 0.910 \\
Game & 205 & 142 & 21 & 42 & 0.871 \\
HP & 5 & 2 & 1 & 2 & 0.989 \\
K-Tuin & 10 & 4 & 4 & 2 & 0.989 \\
Kyeroo & 550 & 237 & 197 & 116 & 0.741 \\
LG & 51 & 28 & 16 & 7 & 0.912 \\
Media Markt & 260 & 8 & 217 & 35 & 0.927 \\
Microsoft & 22 & 15 & 4 & 3 & 0.989 \\
Motorola & 5 & 2 & 2 & 1 & 0.989 \\
Pc Box & 16 & 8 & 2 & 6 & 0.989 \\
PC Componentes & 218 & 191 & 18 & 9 & 0.731 \\
Samsung & 34 & 7 & 2 & 25 & 0.825 \\
The Phone House & 79 & 24 & 17 & 38 & 0.806 \\
Worten & 117 & 41 & 29 & 47 & 0.790 \\
\hline
\end{tabular}


Finally, the results of TA using opinion mining (OM) and data mining techniques are presented in Tables 5-7. Here, based on the analysis of each database classified according to the sentiment and the identified topic, we identified key indicators and insights related to positive, negative, and neutral topics [38].

Table 5. Textual analysis (TA) indicators of positive topics.

\begin{tabular}{lll}
\hline Topic & Key Indicators & WP \\
\hline Exclusive promotions (EP) & $\begin{array}{l}\text { Offers and promotions on Black Friday that users believe } \\
\text { to be real are those that have a limited time (in hours or } \\
\text { minutes) and that customers perceive as exclusive. }\end{array}$ & 3.92 \\
\hline Smartphones (SM) & $\begin{array}{l}\text { Offers and promotions positively commented upon on \# } \\
\text { are related to smartphones and related products. }\end{array}$ & 2.97 \\
\hline
\end{tabular}

Table 6. TA indicators of negative topics.

\begin{tabular}{llc}
\hline Topic & Key Indicators & WP \\
\hline Fraud (FA) & $\begin{array}{l}\text { Companies' frauds commented upon by Twitter users are directly } \\
\text { linked to companies' names. A negative reputation of a company } \\
\text { can causes a decline of the brand in digital ecosystems. }\end{array}$ & 4.21 \\
\hline Insults and Noise (IN) & $\begin{array}{l}\text { Negative contents, such as insults and noise, are generated by } \\
\text { brands when their strategies are fictitious and when unreal } \\
\text { promotions are detected. }\end{array}$ & 3.01 \\
\hline Customer Support (CS) & $\begin{array}{l}\text { Although brands try to provide customer support through social } \\
\text { network interactions, it is not enough, since customer support } \\
\text { actions towards dissatisfied customers are not effective. }\end{array}$ & 1.09 \\
\hline
\end{tabular}

Table 7. TA indicators analysis of neutral topics.

\begin{tabular}{llc}
\hline Topic & Key Indicators & WP \\
\hline Offers and Discounts (OD) & $\begin{array}{l}\text { Offers and discounts on products and services are key for } \\
\text { an appropriate strategy in social media at events such as } \\
\text { Black Friday; however, this does not mean that such } \\
\text { offers and discounts are perceived positively. }\end{array}$ & 4.50 \\
\hline Computers Accessories (CA) & $\begin{array}{l}\text { Along with mobile telephony, most relevant offers on } \\
\text { social networks related to Black Friday are those related } \\
\text { to computers and accessories for bookkeepers. }\end{array}$ & 2.41 \\
\hline
\end{tabular}

\section{Discussion}

An intriguing finding in our results is that, in the identified topics, invariably positive results were obtained only for exclusive promotions and smartphones topics. This finding is not consistent with previous studies, such as Bell et al. [10] who argued that in the eventual content that companies launch on social networks and that aims to promote specific events should have a pleasant, dynamic, and positive tone so that users perceive it as such.

We identified a total of seven different topics related to the content generated by companies. We found that companies base their communication in social networks on offering products and services and exclusive promotions. This tactic is not appropriate if we consider the results reported by Herráez et al. [6], as companies have to try to generate content to interact with users and to create lasting relationships with them through these new digital channels. The results of using this strategy are consequently negative.

We discovered that three topics were negatively perceived by Twitter users, and these topics were related to frauds and offers that were not real. To make things worse, these contents were published 
by companies directly. The negative UGC about such offers clearly harmed online reputation of corresponding brands [50].

Furthermore, based on the results of sentiment analysis, we can conclude that the companies associated with the most positive sentiment in Twitter UGC are Amazon, Game, Kyberoo, and PC Components. A detailed analysis of the UGC associated with these companies demonstrated that these companies were able to establish relationships with customers based on the offers and even launched personalized discounts based on user interaction or engagement in social networks with the brand itself [10]. Therefore, we can see that some companies' attempt to establish a relationship with users through Twitter to increase positive feelings about corresponding brands [59].

However, in the case of Amazon, which obtained highly positive results, some user feedback was also negative. In part, this result can be attributed to the fact that our study period coincided with a strike of the company's employees who used the company's name as hashtag to generate content and to create narrative noise about Amazon in the Black Friday week event.

With regard to negative feelings, in our results, the worst strategies were developed by Media Markt and El Corte Inglés companies, whose contents linked to fraud and unrealistic offers obtained the strongest negative perceptions among Twitter users [60].

As demonstrated by our results, users can get organized into communities to fight against brands [29]. Users feel cheated by false offers in social media-e.g., those where customers are told that they can purchase something with an exclusive discount, while in fact the price has always been the same (see Mangold et al. [61] and Berland et al. [62] for similar results).

With regard to positive sentiments in the Twitter-based UGC analyzed, our results demonstrate that companies should generate exclusive promotions based on limited time horizons, where the discounts are real (see Hoffman and Fodor [63]). In addition, on Black Friday, companies should also focus on products such as smartphones and its accessories [4].

Concerning negative insights derived from our results, the present study demonstrates that companies should follow certain rules in their marketing strategies. In the first place, companies should avoid playing tricks where they raise the price of their products one week before the event and then subsequently lower the price to highlight the reduction as a discount (which is not real, in that case) to influence the consumer behavior. At present, this is a standardized tactic in commercial and strategic marketing [60]; however, it should be used after a careful consideration of the type of social network and user profile on the Internet [14]. Acting so creates a link of a company with fraud, as has already happened in the case of Media Markt and El Corte Inglés.

The consequences of the aforementioned strategy include users' insults and noise, which makes it very difficult for customer support to change the situation, as users who feel cheated create a negative attitude among customers towards the company. These consumers may feel cheated [58], which may increase the number of dissatisfied customers [10].

Finally, key points that generate noise and are not perceived as positive marketing actions are related to offers and discounts that are not truly exclusive and are merely standard discounts. In this respect, our findings are consistent with those reported by Hoffman and Fodor [63], showing that these marketing and sales promotion strategies in social networks should be taken into account [64].

Likewise, trying to boost sales of products such as computers and accessories does not generate enthusiasm among users and is not perceived as an effective tactic by customers [65-67]. This fact must be carefully considered by company executives willing to participate in temporary events based on offers and discounts published on the Internet [68-70].

\section{Conclusions}

In the present study, we developed a novel and original data analysis process that aims to identify digital marketing strategies based on promotions. Our specific focus was on Black Friday 2018 in Spain. We analyzed the contents published by technology companies on Black Friday 2018, including user generated content about offers and discounts, exclusive promotions, as well as fraud and insults and 
noise. Therefore, we explored several tactics and strategies that companies should follow in social networks to succeed in events similar to Black Friday.

We also identified activities that companies should avoid, since such activities generate uncertainty and negative feelings in users who, in turn, speak negatively of companies and share their negative experiences with the digital community by publishing negative UGC. Such negative feedback affects the digital reputation of companies and generates negative perceptions of their offers and discounts, thus reducing the profitability of its shares.

Regarding the three research questions addressed, in RQ1 we identified and codified the main topics related to the engagement of UGC with the companies (EP, SM, FA, IN, CS, OD, CA). As to the second research question (RQ2), our results suggest that the most significant contribution of our findings is the importance of the company's skill to establish relationships with their users through social networks, in the medium and long-term. In the event of a crisis or failed communication between users and brands, companies should carefully consider the criticisms of user communities in social networks and try to make neutral or positive engagement based in the company's relationship with users in digital environment. If these strategies are not implemented correctly, the public image of the company on social networks can be damaged. The power of user communities and their opinions can quickly viralize, causing reputational losses arising from negative feelings expressed by users in their UGC. Finally, concerning the third research question (RQ3), our results provide meaningful insights about the companies' strategies of promotion in social networks. Our findings can serve as guidelines of good practices for specific events developed through social networks.

\subsection{Theoretical Implications}

Regarding the theoretical implications of this study, it should be noted that, out of the seven topics that were identified, three topics (EC, PS and OD) could be used in further research as independent variables or constructs to establish statistical relationship in models developed with partial least squares structural equation modeling (PLS-SEM), SPSS, or Analysis of Moment Structures (AMOS), among other quantitative analysis methods.

Therefore, our identification of the topics makes an important theoretical contribution to this research area if we consider the exploratory approach developed based on topic discovery. The remaining topics should be carefully considered by researchers when developing studies based on systematic literature reviews or case studies, among other methods.

In addition, in the present study, novel approaches to brands and their reputation on social networks considering UGC reactions and behavior, have been discovered and confirmed. The original method used can be applied in further research to extract or discover additional knowledge with the analyzed UGC sample and additional big data analytics techniques.

Academic researchers should keep in mind that machine learning technology and SVMs are growing exponentially, and new methods and approaches must be applied to improve the reliability of the results and to obtain additional insights.

\subsection{Managerial Implications}

As indicated by Buckley and Casson [23] decision making is vital for success in marketing strategies. Likewise, Cody et al. [16] argued that these strategies should be specially designed for digital environments and social networks. Based on these conclusions, executives of technology companies, SMEs, or companies focused on both Business to Consumer (B2C) or Business to Business (B2B) can use the results of this research to understand user behavior in social networks such as Twitter.

Specifically, executives can use the results to understand how they should develop and implement their promotional strategies on Twitter, as well as how they should interact with users with regard to the published content to increase the positive engagement.

Moreover, in the technology sector and beyond, the executives or directors of digital marketing companies that participate in social network events where promotions and offers are made can better 
understand the main topics and use them in their favor and obtain insights that help them improve their strategies; similarly, they can also avoid possible crises or situations that could cause damage to their reputation and value in these digital ecosystems.

The limitations of the present study are related to the size of the sample and the country analyzed (Spain). In further research, it would be meaningful to use the same approach to investigate UGC from other EU countries, or to compare user content from different countries. Another limitation of the present study is related to the automatic identification of topics and feelings related to Black Friday 2018 event using SVM. In the future, our results can be used by other researchers for comparative and evolutionary studies of these actions with a focus on other social networks.

Author Contributions: J.R.S, A.R.-M. and P.P.-S. conceived and designed the review; J.R.S. performed the methodology; A.R.-M. and P.P.-S. analyzed the results; J.R.S., A.R.-M. and P.P.-S. wrote the paper.

Funding: This research received no external funding.

Conflicts of Interest: The authors declare no conflict of interest.

\section{References}

1. Helm, S. Viral marketing-establishing customer relationships by 'word-of-mouse'. Electron. Mark. 2000, 10, 158-161. [CrossRef]

2. Tan, X.; Yen, D.C.; Fang, X. Internet integrated customer relationship management a key success factor for companies in the e-commerce arena. J. Comput. Inf. Syst. 2002, 42, 77-86.

3. Flyverbom, M.; Deibert, R.; Matten, D. The Governance of Digital Technology, Big Data, and the Internet: New Roles and Responsibilities for Business. Bus. Soc. 2019, 58, 3-19. [CrossRef]

4. Huda, M.; Qodriah, S.L.; Rismayadi, B.; Hananto, A.; Kardiyati, E.N.; Ruskam, A.; Nasir, B.M. Towards Cooperative with Competitive Alliance: Insights into Performance Value in Social Entrepreneurship. In Creating Business Value and Competitive Advantage with Social Entrepreneurship; IGI Global: Hershey, PA, USA, 2019; pp. 294-317.

5. Saura, J.R.; Bennett, D.R. A Three-Stage method for Data Text Mining: Using UGC in Business Intelligence Analysis. Symmetry 2019, 11, 519. [CrossRef]

6. Herráez, B.; Bustamante, D.; Saura, J.R. Information classification on social networks. Content analysis of e-commerce companies on Twitter. Espacios 2017, 38, 16.

7. Manso, M.; Manso, B. The role of social media in crisis: A European holistic approach to the adoption of online and mobile communications in crisis response and search and rescue efforts. In Strategic Intelligence Management; Butterworth-Heinemann: Cambridge, UK, 2013; pp. 93-107.

8. Palos-Sanchez, P.; Saura, J.R.; Martin-Velicia, F. A study of the effects of Programmatic Advertising on users' Concerns about Privacy overtime. J. Bus. Res. 2019, 96, 61-72. [CrossRef]

9. Boyd Thomas, J.; Peters, C. An exploratory investigation of Black Friday consumption rituals. Int. J. Retail Distrib. Manag. 2011, 39, 522-537. [CrossRef]

10. Bell, G.C.; Weathers, M.R.; Hastings, S.O.; Peterson, E.B. Investigating the celebration of Black Friday as a communication ritual. J. Creat. Commun. 2014, 9, 235-251. [CrossRef]

11. Saura, J.R.; Reyes-Menendez, A.; Palos-Sanchez, P. Un Análisis de Sentimiento en Twitter con Machine Learning: Identificando el sentimiento sobre las ofertas de\# BlackFriday. Rev. Espac. 2018, 39, 75.

12. Thelwall, M.; Buckley, K.; Paltoglou, G. Sentiment in Twitter events. J. Am. Soc. Inf. Sci. Technol. 2011, 62, 406-418. [CrossRef]

13. Pruett, M. The Global Black Friday Report: Trends, Data, Strategy. Available online: https://www.criteo.com/ insights/black-friday-report-2018/ (accessed on 29 January 2019).

14. Wilson, M.; Paschen, J.; Pitt, C.; Wallström, Å. Restraint on Black Friday: An Investigation into Consumer Motivations for Participating in "Buy Nothing Day": An Abstract. In Academy of Marketing Science World Marketing Congress; Springer: Cham, Switzerland, 2018; p. 859.

15. Choi, D.; Kim, P. Sentiment analysis for tracking breaking events: A case study on twitter. In Asian Conference on Intelligent Information and Database Systems; Springer: Berlin/Heidelberg, Germany, 2013; pp. 285-294.

16. Cody, E.M.; Reagan, A.J.; Dodds, P.S.; Danforth, C.M. Public opinion polling with Twitter. arXiv 2016, arXiv:1608.02024. 
17. Ahsan, U.; De Choudhury, M.; Essa, I. Towards using visual attributes to infer image sentiment of social events. In Proceedings of the 2017 International Joint Conference on Neural Networks (IJCNN), Anchorage, AK, USA, 14-19 May 2017; pp. 1372-1379.

18. Killian, G.; McManus, K. A marketing communications approach for the digital era: Managerial guidelines for social media integration. Bus. Horiz. 2015, 58, 539-549. [CrossRef]

19. He, W.; Wu, H.; Yan, G.; Akula, V.; Shen, J. A novel social media competitive analytics framework with sentiment benchmarks. Inf. Manag. 2015, 52, 801-812. [CrossRef]

20. Kim, S.; Kandampully, J.; Bilgihan, A. The influence of eWOM communications: An application of online social network framework. Comput. Hum. Behav. 2018, 80, 243-254. [CrossRef]

21. Zhang, Z.; Liang, S.; Li, H.; Zhang, Z. Booking now or later: Do online peer reviews matter? Int. J. Hosp. Manag. 2019, 77, 147-158. [CrossRef]

22. Kettinger, W.J.; Teng, J.T.; Guha, S. Business process change: A study of methodologies, techniques, and tools. MIS Q. 1997, 21, 55-80. [CrossRef]

23. Buckley, P.; Casson, M. Decision-making in international business. J. Int. Bus. Stud. 2019, 2, 1-16. [CrossRef]

24. Vyas, V.; Uma, V. Approaches to sentiment analysis on product reviews. In Sentiment Analysis and Knowledge Discovery in Contemporary Business; IGI Global: Hershey, PA, USA, 2019; pp. 15-30.

25. Ragini, J.R.; Anand, P.R.; Bhaskar, V. Big data analytics for disaster response and recovery through sentiment analysis. Int. J. Inf. Manag. 2018, 42, 13-24. [CrossRef]

26. Shahijan, M.K.; Rezaei, S.; Amin, M. Qualities of effective cruise marketing strategy. Int. J. Qual. Reliab. Manag. 2018, 35, 2304-2327. [CrossRef]

27. Hudson, S.; Huang, L.; Roth, M.S.; Madden, T.J. The influence of social media interactions on consumer-brand relationships: A three-country study of brand perceptions and marketing behaviors. Int. J. Res. Mark. 2016, 33, 27-41. [CrossRef]

28. Crowston, K.; Fagnot, I. Stages of motivation for contributing user-generated content: A theory and empirical test. Int. J. Hum.-Comput. Stud. 2018, 109, 89-101. [CrossRef]

29. Ukpabi, D.C.; Karjaluoto, H. What drives travelers' adoption of user-generated content? A literature review. Tour. Manag. Perspect. 2018, 28, 251-273. [CrossRef]

30. Acar, A.S.; Polonsky, M. Online social networks and insights into marketing communications. J. Internet Commer. 2007, 6, 55-72. [CrossRef]

31. Hanna, R.; Rohm, A.; Crittenden, V. We're all connected: The power of the social media ecosystem. Bus. Horiz. 2011, 54, 265-273. [CrossRef]

32. Stewart, B. Open to influence: What counts as academic influence in scholarly networked Twitter participation. Learn. Media Technol. 2015, 40, 287-309. [CrossRef]

33. Shuai, X.; Liu, X.; Xia, T.; Wu, Y.; Guo, C. Comparing the pulses of categorical hot events in twitter and weibo. In Proceedings of the 25th ACM Conference on Hypertext and Social Media, Santiago, Chile, 1-4 September 2014; pp. 126-135.

34. Chen, J. Search engine For Twitter Sentiment Analysis. Ph.D. Thesis, University of Texas at Austin, Austin, TX, USA, 2015.

35. Khodabakhsh, M.; Kahani, M.; Bagheri, E.; Noorian, Z. Detecting life events from twitter based on temporal semantic features. Knowl.-Based Syst. 2018, 148, 1-16. [CrossRef]

36. Zhou, X.; Tao, X.; Yong, J.; Yang, Z. Sentiment analysis on tweets for social events. In Proceedings of the 2013 IEEE 17th International Conference on Computer Supported Cooperative Work in Design (CSCWD), Whistler, BC, Canada, 27-29 June 2013; pp. 557-562.

37. Tsolmon, B.; Kwon, A.R.; Lee, K.S. Extracting social events based on timeline and sentiment analysis in twitter corpus. In Natural Language Processing and Information Systems; Springer: Berlin/Heidelberg, Germany, 2012; pp. 265-270.

38. Tsytsarau, M.; Palpanas, T.; Castellanos, M. Dynamics of news events and social media reaction. In Proceedings of the 20th ACM SIGKDD International Conference on Knowledge Discovery and Data Mining, New York, NY, USA, 24-27 August 2014; pp. 901-910.

39. Reyes-Menendez, A.; Saura, J.R.; Alvarez-Alonso, C. Understanding \#WorldEnvironmentDay User Opinions in Twitter: A Topic-Based Sentiment Analysis Approach. Int. J. Environ. Res. Public Health 2018, 15, 2537.

40. Saura, J.R.; Palos-Sanchez, P.R.; Grilo, A. Detecting Indicators for Startup Business Success: Sentiment Analysis using Text Data Mining. Sustainability 2019, 15, 917. [CrossRef] 
41. Raghavendra, T.S.; Mohan, K.G. Web Mining and Minimization Framework Design on Sentimental Analysis for Social Tweets Using Machine Learning. Procedia Comput. Sci. 2019, 152, 230-235. [CrossRef]

42. Alfrjani, R.; Osman, T.; Cosma, G. A Hybrid Semantic Knowledgebase-Machine Learning Approach for Opinion Mining. Data Knowl. Eng. 2019, 121, 88-108. [CrossRef]

43. Saura, J.R.; Rodriguez Herráez, B.; Reyes-Menendez, A. Comparing a traditional approach for financial Brand Communication Analysis with a Big Data Analytics technique. IEEE Access 2019, 7, 37100-37108. [CrossRef]

44. Reyes-Menendez, A.; Saura, J.R.; Martinez-Navalon, J.G. The impact of e-WOM on Hotels Management Reputation: Exploring TripAdvisor Review Credibility with the ELM model. IEEE Access 2019, 7, 68868-68877. [CrossRef]

45. Wirtz, J.; Den Ambtman, A.; Bloemer, J.; Horváth, C.; Ramaseshan, B.; Van De Klundert, J.; Kandampully, J. Managing brands and customer engagement in online brand communities. J. Serv. Manag. 2013, 24, $223-244$. [CrossRef]

46. Pritchard, J.K.; Stephens, M.; Donnelly, P. Inference of population structure using multilocus genotype data. Genetics 2000, 155, 945-959. [PubMed]

47. Blei, D.M.; Ng, A.Y.; Jordan, M.I.; Lafferty, J. Latent Dirichlet Allocation. J. Mach. Learn. Res. 2003, 3, 993-1022.

48. Krippendorff, K. Bivariate Agreement Coefficients for Reliability Data. In Sociological Methodology; Borgatta, E.R., Bohrnstedt, G.W., Eds.; Jossey Bass, Inc.: San Francisco, CA, USA, 1970; Volume 2, pp. 139-150.

49. Sandelowski, M. Sample size in qualitative research. Res. Nurs. Health 1995, 18, 179-183. [CrossRef] [PubMed]

50. Morgan-Thomas, A.; Veloutsou, C. Beyond technology acceptance: Brand relationships and online brand experience. J. Bus. Res. 2013, 66, 21-27. [CrossRef]

51. Jia, S. Leisure Motivation and Satisfaction: A Text Mining of Yoga Centres, Yoga Consumers, and Their Interactions. Sustainability 2018, 10, 4458. [CrossRef]

52. Yu, C.H.; Jannasch-Pennell, A.; DiGangi, S. Compatibility between text mining and qualitative research in the perspectives of grounded theory, content analysis, and reliability. Qual. Rep. 2011, 16, 730-744.

53. Krippendorff, K. Measuring the reliability of qualitative text analysis data. Qual. Quant. 2004, 38, 787-800. [CrossRef]

54. Liu, B.; Zhang, L. A survey of opinion mining and sentiment analysis. In Mining Text Data; Springer: Boston, MA, USA, 2012; pp. 415-463.

55. Fayyad, U.; Piatetsky-Shapiro, G.; Smyth, P. From data mining to knowledge discovery in databases. AI Mag. 1996, 17, 37.

56. Wu, X.; Kumar, V.; Quinlan, J.R.; Ghosh, J.; Yang, Q.; Motoda, H.; Zhou, Z.H. Top 10 algorithms in data mining. Knowl. Inf. Syst. 2008, 14, 1-37. [CrossRef]

57. Krippendorff, K. Reliability. In Content Analysis; An Introduction to Its Methodology, 2nd ed.; Krippedorff, K., Ed.; Sage Publications: Thousand Oaks, CA, USA, 2004; pp. 211-256.

58. Scott, D.M. The New Rules of Marketing and PR: How to Use Social Media, Online Video, Mobile Applications, Blogs, News Releases, and Viral Marketing to Reach Buyers Directly; John Wiley and Sons: Hoboken, NJ, USA, 2015.

59. Ashley, C.; Tuten, T. Creative strategies in social media marketing: An exploratory study of branded social content and consumer engagement. Psychol. Mark. 2015, 32, 15-27. [CrossRef]

60. Cheong, F.; Cheong, C. Social Media Data Mining: A Social Network Analysis of Tweets During The 2010-2011 Australian Floods. PACIS 2011, 11, 46.

61. Mangold, W.G.; Faulds, D.J. Social media: The new hybrid element of the promotion mix. Bus. Horiz. 2009, 52, 357-365. [CrossRef]

62. Berland, L.; Forman, S.; Gebb, L.; Koul, P.; Muthukrishnan, S.; Russo, J.; Wolf, D.U.S. System and Method for Providing Offers Through a Social Media Channel. U.S. Patent 9,934,537, 12 July 2013.

63. Hoffman, D.L.; Fodor, M. Can you measure the ROI of your social media marketing? MIT Sloan Manag. Rev. 2010, 52, 41 .

64. Tuten, T.L.; Solomon, M.R. Social Media Marketing; Sage: New Delhi, India, 2017.

65. Reyes-Menendez, A.; Saura, J.R.; Palos-Sanchez, P.R.; Alvarez-Garcia, J. Understanding User Behavioral Intention to Adopt a Search Engine that Promotes Sustainable Water Management. Symmetry 2018, 10, 584. [CrossRef] 
66. Palos-Sanchez, P.; Martin-Velicia, F.; Saura, J.R. Complexity in the Acceptance of Sustainable Search Engines on the Internet: An Analysis of Unobserved Heterogeneity with FIMIX-PLS. Complexity 2018, 2018, 6561417. [CrossRef]

67. Lennon, S.J.; Kim, M.; Lee, J.; Johnson, K.K. Consumer Emotions on Black Friday: Antecedents and Consequence. J. Res. Consum. 2018, 32, 70-109.

68. Woo, J.; Kim, E.; Sung, T.-E.; Lee, J.; Shin, K.; Lee, J. Developing an Improved Risk-Adjusted Net Present Value Technology Valuation Model for the Biopharmaceutical Industry. J. Open Innov. Technol. Mark. Complex. 2019, 5, 45. [CrossRef]

69. Joueid, A.; Coenders, G. Marketing Innovation and New Product Portfolios. A Compositional Approach. J. Open Innov. Technol. Mark. Complex. 2018, 4, 19. [CrossRef]

70. Kwon, Y.-I.; Son, J.-K. A Case Study on the Promising Product Selection Indicators for Small and Medium-Sized Enterprises (SMEs). J. Open Innov. Technol. Mark. Complex. 2018, 4, 56. [CrossRef]

(C) 2019 by the authors. Licensee MDPI, Basel, Switzerland. This article is an open access article distributed under the terms and conditions of the Creative Commons Attribution (CC BY) license (http://creativecommons.org/licenses/by/4.0/). 